\title{
The Use of Seclusion in a DHSS Youth Treatment Centre
}

\author{
Greg Wilkinson, Senior Registrar, Maudsley Hospital; currently Research Psychiatrist, MRC Unit for Epidemiological \\ Studies in Psychiatry, University of Edinburgh
}

Seclusion, locking up patients in isolation, has a long history in psychiatry (Hunter and MacAlpine, 1963). John Conolly (1856), for example, though an advocate of nonrestraint, defended the practice: 'That salutory exclusion of causes of excitement from an already irritated brain, has been so unjustly stigmatized as solitary imprisonment'. Even so, many of his contemporaries reviled seclusion. Indeed, experience over the years has shown that such limitations of patients' liberty need to be carried out under scrutiny, otherwise abuses may take place. Patients who give staff trouble may be secluded as a punishment or kept in seclusion for long periods without proper attention. For this reason, therefore, doctors need always to take particular care to see that this form of management is carefully regulated.

Nowadays, patients are secluded for two main reasons. Firstly, usually in an emergency when their disturbed behaviour is unresponsive to standard treatment and is putting their safety, and the safety of the ward environment, at risk. Secondly, perhaps less commonly, when patients have agreed to this sanction as part of a behaviour modification programme (the so-called 'time out'). But in clinical practice there is sometimes little to distinguish between these two uses, and in the event, a disruptive patient is often secluded by staff in the hope that he might spontaneously settle down. Whatever the circumstances are, the outcome is that an ill person may be isolated from human contact in a bare room with little in the way of environmental stimulation for an unspecified time. In addition to such privation, everyday clothing and footwear is generally removed from secluded patients, and they may be left naked or in night attire. They may also be deprived of the ability to exercise, go to the toilet, or to eat and drink, except in a limited way. Not surprisingly, then, there is still much concern about the use of seclusion in the NHS (Strutt et al, 1980; Davis, 1982).

A recent Bulletin article (Royal College of Psychiatrists, 1982) drew attention to the need for hospitals to review their seclusion policies. This article is intended to widen the discussion of these matters by bringing notice to the use of seclusion in a non-NHS treatment unit which is run by the DHSS.

\section{St Charles}

This Youth Treatment Centre was opened at Brentwood, Essex, in 1971. It is one of two national facilities (the other is Glenthorne, opened in 1978) which are designed to care for the needs of those disturbed children and adolescents who are too disruptive to be housed in community houses, hospitals, or in other statutory residential accommodation. Between them the two institutions have the whole of the UK as a catchment area. Applications for admission are administered by the Children's division of the DHSS in London, and come from two sources: social services departments, for children under care orders, and from the Home Office (indirectly, from the Courts). The overriding reason for admission to St Charles is that the child needs to be cared for in conditions of security.

The majority of those who are admitted to St Charles have a life-long history of disturbed social behaviour. A smaller group are admitted because they have committed serious offences such as murder or arson, and are to be held in security under a Crown Court order (Section 53 of the Children's and Young Persons' Act of 1933). None are considered 'ill' in terms of formal psychiatric illness. The youngest admission, to date, was aged 10, and the oldest, 16. At admission, the average age is between 14 and 15 years: the children stay, on average, for three years. After release there is a limited follow-up, though those subject to Indeterminate Section 53 Orders are on licence for life.

All told, St Charles has places for $\mathbf{3 0}$ children; the males and females are housed together and have single bedrooms in three separate modern units. The highly trained staff are drawn from the psychiatric nursing, child care and teaching professions. There is also a full-time clinical psychologist, two full-time senior social workers and a community medical officer, who screens the children. A local GP visits weekly and covers for medical emergencies. The part-time visiting psychiatrist sees all Section 53 children. He is also available to see any of the other children who are causing concern, and he acts in a general advisory capacity in staff support and case discussion meetings. Ample educational and recreational opportunities are provided on the site.

Overall, the aim is to effect behavioural and emotional changes in the youngsters by exposing them to a therapeutic milieu of a psychodynamic type.

\section{Security and seclusion}

St Charles is easily reached along a country lane, a quarter of a mile from Brentwood. The approach is not at all forbidding and the campus is not enclosed by anything more sinister than large trees. Of the three houses, House 1, with 10 places, is the secure and locked unit. When I visited the unit, seven of the nine residents were detained under Section 53 Orders because they had committed very grave offences. Children in the other two houses are given more freedom and greater personal responsibility.

There are two suites of secure rooms for seclusion in House 1, one on each wing, and each is made up of three secure rooms. toilet and bathroom. Non-secluded children in the house cannot gain access to these suites. Houses II and III have only one such secure room each. These are on the 
main corridors of the houses, next to the other bedrooms, but they do not have separate toilets or bathrooms. All members of these houses have access to the doors of the secure rooms; and, in House III, the secure room is adjacent to the staff office, which is at the hub of the house activity. Secluded children in House I are therefore physically separated from the rest of the household, but this is not the case in the other houses.

The seclusion rooms have bare walls and floors and are about five square metres in size. Natural light enters the rooms through large, single-pane strengthened plastic windows, which mostly overlook the extensive grounds. There are no bars on these windows, but they are treated with a reflecting material so that the interior of the rooms is not visible from the exterior. The reinforced doors have viewing panels set into them. The rooms have no furniture. For sleeping, the children are given a non-destructible mattress and blankets. Normal clothing is only permitted in the rooms if the likelihood of self-injury is thought by the staff to be small; in some cases the children need to be provided with nightwear instead. Meals and drinks are brought to the seclusion room, as necessary. However, if the children have to wash or go to the toilet, they have to be accompanied from the room by staff and then returned. Each room has an emergency bell which a child, or staff member, can press to attract attention.

Seclusion at St Charles is used very rarely. Its chief use is for youngsters whose behaviour is unmanageable by ordinary means and only after the whole range of child care skills has proved to be of no avail. Psychotropic medication is virtually never used. Typically, the decision to seclude a child is taken by a house leader, his deputy, or the on-call management worker. Thereafter, there is consultation with the management (the director or his deputy) and advisory staff (the psychologist, psychiatrist, or social worker) about the necessity for the continuation of the process. The house staff (and sometimes the children) also meet to discuss the incident and the reasons and need for the seclusion. It is the house leader who usually makes the decision to stop seclusion, once the affected child has calmed down, after discussion with senior management.

While in seclusion, the children are visited every 15 minutes, and this procedure is the responsibility of the house staff on duty. All contacts with the child are logged on an official record (which is later sent to the DHSS), and a member of staff is designated for this duty. In all circumstances members of staff will go into the seclusion room with the child, to talk with him or comfort him, and to enable him to gain insight into the reasons for his disturbed behaviour. Seclusion is seen as a containing and nurturing experience by staff, an opportunity to develop necessary dependence, and is by and large seen in the same way by the child. There is, however, great variability in the duration of seclusion; on average a child may be secluded for about 12 hours, with a range from a couple of hours to a couple of days. Those who need to be kept in seclusion for longer than a day are seen by the management and advisory staff.

Occasionally, the secure rooms are used for other purposes-as a bedroom, for example, for a young person who has made his own room unsafe, or when a child has wilfully indulged in extremely dangerous behaviour. Finally, the children's bedrooms are sometimes used for seclusion after less grave incidents, or for a transitory period, after seclusion in a secure room.

\section{Comment and comparison}

The practice of seclusion at St Charles may usefully be compared with that in the NHS. Campbell et al (1982) have described the use of seclusion in a 25-bed long-stay ward for the treatment of disturbed and aggressive female patients. Their survey was conducted at Kingseat Hospital in rural Aberdeenshire. There the senior nurse on duty had responsibility for initiating seclusion, and later, he or she informed the duty doctor and nursing officer of the reason for seclusion. The senior nurse also made a report when the patient was released. Full details of the seclusion were then sent to the divisional nursing officer. Two side rooms on the ward were used for seclusion. These were about 12 feet by 9 feet in size, and contained only a fixed wooden bed-base with a mattress. The rooms were painted grey. Lighting came from an armour-plated window and from a ceiling light, which was controlled from outside the room. The room was, of course, locked from without; however, nurses observed the patients approximately every 15 minutes through a fisheye lens set in the door.

The patients were secluded for a variety of reasons. The most frequently cited grounds for seclusion were physical violence to property and displays of aggression to staff. But verbal abuse of staff, physical violence to patients, threatened violence, generally disturbed behaviour, absconding, and disruption of the ward rules or routine were also commonly quoted by the nurses. In the study year there were 69 incidents of seclusion; these involved 15 patients $(9$ patients of whom were on Section 24 of the Mental Health Act (Scotland) 1960). In half the episodes the patients were secluded for less than an hour, and in a quarter of episodes, for more than two hours. The longest period of seclusion was 23 hours; the average seclusion lasted two and a half hours. Interestingly, the authors noted that seclusion was used more frequently on days when the nursing shifts changed than on other days. In addition, the crises which resulted in seclusion tended to occur more often at mealtimes ( 35 incidents) than at other times of the day or night.

The patients were unaccompanied throughout the seclusion in 90 per cent of the incidents. But on only two occasions did a patient suffer physical injury in the room: once, a patient attempted to hang herself; another time, a patient removed sutures from her wrist. Whilst in seclusion, patients were usually settled and co-operative, though a few continued to be abusive and violent. Finally, after release 
from the seclusion room, over two-thirds of patients were quiet and constructive in their behaviour (nevertheless, a quarter continued to be disruptive).

In conclusion, the poverty of the literature on seclusion (Wilkinson, 1983) shows clearly that the topic has been neglected as a subject for open discussion. There is little cause for us to believe that such neglect is justifiable.

\section{ACKNOWLEDGEMENTS}

I wish to thank Mr S. G. T. Edwards, the Director of St Charles, and Peter E. Hodgkinson, Senior Clinical Psychologist, for their help during my visit. The views expressed here are my own.

REFERENCES

Camprell, W., Shepherd, H. \& Falconer, F. (1982) The use of seclusion. Nursing Times, 78, 1821-5.

CoNolly, J. (1856) Treatment of the Insane without Mechanical Restraints. (Reprinted with introduction by R. Hunter and I. MacAlpine). Folkestone and London: Dawsons of Pall Mall.

DAvis, T. (1982) Parliamentary question. Hansard, vol. 33, col. 398 W.

Hunter, R. \& MACAlpINE, I. (1963) Three Hundred Years of Psychiatry, 1535-1860. London: Oxford University Press.

Royal College of Psychiatrists (1982) Locking up patients by themselves. Bulletin of the Royal College of Psychiatrists, 6 , 199-200.

Strutt, R. et al (1980) Seclusion: can it be justified? Nursing Times, 76, 1629-33.

WILKInson, G. (1983) Locking up psychiatric patients. British Medical Journal, 286, 581-82.

\section{Trainees' Forum}

\section{The Experience of a Psychotherapy Trainee*}

Felicity de Zulueta, Senior Registrar in Psychotherapy, Maudsley Hospital

I am very pleased to have this opportunity to share with you my experiences as a trainee at the Maudsley Hospital. This training differs from many in that I am a part-time Senior Registrar and a part-time mother. Unlike most children, mine actually opened the doors to my professional aspirations. I became a trainee in a specialty whose clinical approach not only corresponded to the one I wanted to practise, but one which also promised to increase my understanding of human behaviour.

I came to psychotherapy with a French philosophical background and a degree in Biological Sciences. The first has instilled in me the importance of a theoretical basis to my clinical work; practice and theory must constantly be seen to interact with one another. The biological sciences gave me a scientific approach, a knowledge of systems, ecology and ethology which all contribute to my knowledge of human beings.

On reading the Report of the Joint Committee on Higher Psychiatric Training, I found that my training aspirations were very much in line with those recommended. I was fortunate in not only being able to pursue my various interests, but also in getting support and guidance from my seniors.

My history in psychiatry starts with Professor A. Clare. I was doing my elective in the Maudsley when he metaphorically took me by the hand and said in his inimitable Irish way, 'Forget all you have learnt and just listen to what the patient has to say.' I then met Dr M. Jackson and worked on his ward. Here was a man who talked, listened and understood patients as no one had before, in my life. He

- Based on a paper given at a conference of trainers and trainees in psychotherapy at the Royal College of Physicians on 4 November 1982. made sense of so-called 'madness' and he gave me hope (a crucial ingredient to training). Through him I became aware of the need to engage in the long-term psychoanalytic psychotherapy of severely disturbed patients. My early intuitions and curiosity found in the individual psychotherapeutic session a 'laboratory' for the study of human communication.

It was also on Dr Jackson's ward that I became fascinated by the interactions between psychosomatic patients and their therapists. They made me realize, more than any other patients, how ineffectual is the dualistic mind/body paradigm when it comes to understanding mental illness. Through this experience, I learnt how important it is, in the face of so little knowledge, for the various therapeutic approaches both to remain in contact and learn from each other. This realization led me to explore the possibilities offered by family therapy. I had seen how useful it was in its simplest form in the management of chronic patients in community psychiatry. I then discovered that the more refined systems-oriented techniques were therapeutically advantageous to a certain class of patients, such as anorexics.

Family therapy can appear to those outside the field as a jungle of methods and approaches; therein lies its richness and possibly its dangers. Driven by my need to reconcile practice and theory rather than go for the more empirical, I found myself increasingly interested in the Milan approach formulated by Professor Palazzoli and her team. This is an approach created by experienced psychoanalysts steeped in systems theory and geared to the treatment of psychotic patients. I was able to attend their course in Italy and to practise their method in the Maudsley.

Throughout my training in psychiatry I witnessed the potential effectiveness of group therapeutic techniques 